\title{
ECT Internship: Experiencing Privilege, Opportunity, and the Spirit of Giving
}

\author{
By Mengqiao Xu
}

$\mathbf{T}$ he past twelve months have been exciting and memorable. Passing the dissertation defense, graduating with my doctoral degree, and accepting a position are all lifechanging events. However, I must admit that not a single event could compete with the ECT Foundation Internship experience I had at the November 2008 AECT Orlando Convention because none intertwined privilege, opportunity, and the spirit of giving.

From the thrilling moment of being announced as one of the 2008 ECT Cochran Interns, I knew I had an excellent start at becoming an honorable and contributing member of the AECT society. The experience not only recognized my academic achievement as a graduate student in the field and my potential leadership skills, but also granted me the privilege to view myself as a leader and start working as a leader. The special medal served as the all-access pass that opened every single door to me and increased my confidence level. The privilege allowed me to observe, to learn, and to better understand how the AECT leaders work to make excellence happen. The privilege afforded more recognition of my research, my study, and my competencies of becoming successful in the field. And the privilege offered golden opportunities for me to further develop myself as a leader to serve the AECT community.

As a graduate student close to the end of my program of study last fall, the opportunity from the ECT Internship experience was

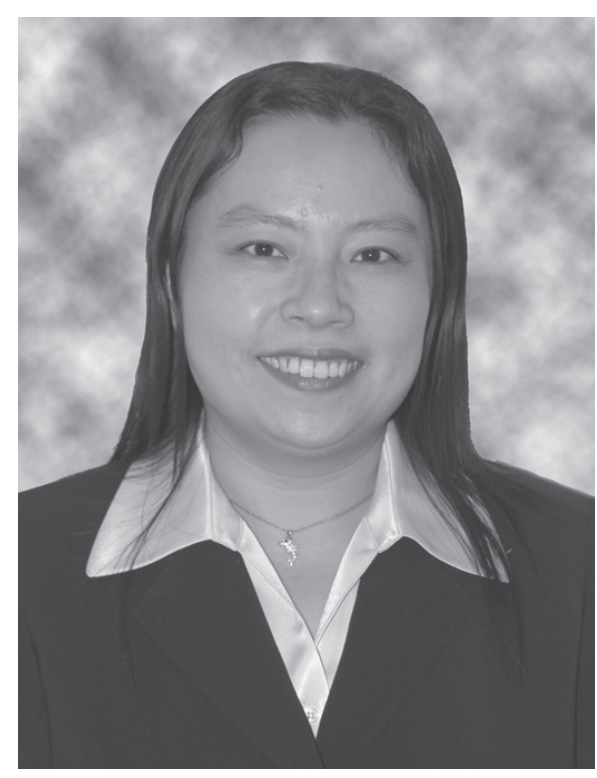

Mengqiao Xu

tremendous. It was a jumpstart to my professional journey with all the elements I needed to become successful. First, being mentored by the leaders and renowned experts in the field on various occasions (the intern breakfast meetings, the division activities, and the conversations with the Intern Coordinators) offered me valuable advice about what to expect and how to perform as a new graduate and a new professional. Second, shadowing and observing how the leaders made their decisions and how they put their ideas into action provided me with unique perspectives that led to the incredible opportunity to reflect on my own vision of the field and of how to make contributions to the organization with my own expertise and point of view. In addition, the connection I made with my fellow interns during the week was another excellent opportunity for me to start collaborating with outstanding young scholars and future leaders from different backgrounds. It might take much longer to build such connections, especially for a student, if it was not for the ECT Internship.

Finally, the most important essence behind the privilege and the opportunities was the spirit of giving. I sensed this spirit the moment I entered AECT, and I have been immersed within this spirit since then. I appreciate the priceless support from the instructional technology faculty at Northern Illinois University who guided me to become an ECT Intern and to achieve all I have. I appreciate all the invaluable giving from the ECT Foundation and AECT that recognized me and challenged me to move closer to my career goals. I plan to perpetuate the spirit of giving by serving the AECT community from a leadership role, by mentoring my students and newcomers to the field, and by making connections with other communities to establish collaboration and partnership with AECT to make AECT a larger and stronger community. I believe with all the privilege, opportunity and spirit of giving the ECT Interns experience, the future of AECT is promising. I am so grateful and proud that I am part of AECT.

\footnotetext{
Mengqiao $\boldsymbol{X u}$ graduated from Northern Illinois University with her Ed.D. in Instructional Technology in May 2009. She is currently working for the university-school partnerships office and also teaching instructional technology courses at NIU.
} 